FAKTOR-FAKTOR YANG MEMPENGARUHI KUALITAS SISTEM INFORMASI ZAKAT

Sistem informasi adalah suatu sistem buatan manusia yang umumnya terdiri dari serangkaian komponen terpadu berbasis komputer dan komponen pengguna didirikan untuk mengumpulkan, menyimpan dan mengelola data dan menghasilkan output informasi kepada pengguna Gelinas, et al., (2008:13). Melalui Sistem Informasi Akuntansi yang berkualitas, user akan memperoleh informasi yang berkualitas pada saat yang tepat untuk pengambilan keputusan. Fenomena yang terjadi pada organisasi di Indonesia menunjukkan bahwa sistem informasi akuntansi belum berkualitas sehingga berdampak pada belum berkualitasnya informasi akuntansi. Kenyataan dilapangan khususnya di Badan Amil Zakat Nasional (BAZNAS), sebagaimana yang diungkapkan oleh Fuad Nashar (2013) sekretaris BAZNAS Pusat bahwa belum tertatanya sistem pelaporan zakat yang terintegrasi secara nasional mengakibatkan laporan keuangan BAZNAS kabupaten dan kota seluruh Indonesia tidak tepat waktu. Demikan pula yang dikemukakan Ketua BAZNAS Pusat (Didin Hafidhuddin, 2014), bahwa belum terintegrasinya database pemberi zakat (muzaki) dan penerima zakat (mustahik) mengakibatkan belum optimalnya penghimpunan dan penyaluran dana zakat di Indonesia. Dalam buku ini secara khusus membahas dan menganalisis seberapa besar pengaruh struktur organisasi, kepemimpinan transformasional, dan kompetensi pengguna terhadap kualitas sistem informasi akuntansi dan dampaknya terhadap kualitas informasi akuntansi pada BAZNAS kabupaten dan kota yang ada di Pulau Jawa.
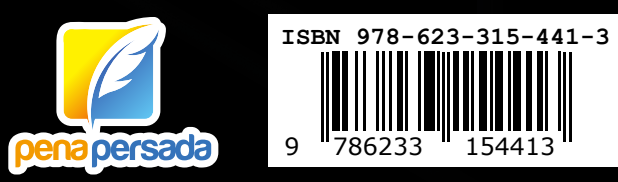

FAKTOR-FAKTOR YANG MEMPENGARUHI KUALITAS SISTEM INFORMASI AKUNTANSI ZAKAT

$>$ NUNUNG NURHAYATI 


\section{FAKTOR-FAKTOR YANG MEMPENGARUHI KUALITAS SISTEM INFORMASI AKUNTANSI ZAKAT}

NUNUNG NURHAYATI

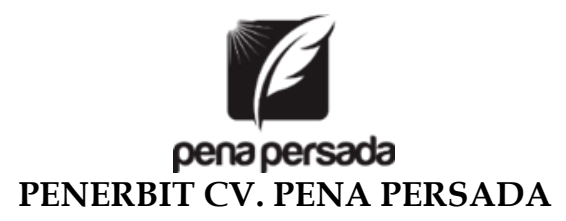




\title{
FAKTOR-FAKTOR \\ YANG MEMPENGARUHI KUALITAS \\ SISTEM INFORMASI AKUNTANSI ZAKAT
}

\author{
Penulis: \\ Nunung Nurhayati
}

ISBN: 978-623-315-441-3

Editor:

Wiwit Kurniawan

Design Cover:

Retnani Nur Briliant

Layout:

Nisa Falahia

\section{Penerbit CV. Pena Persada}

Redaksi:

Jl. Gerilya No. 292 Purwokerto Selatan, Kab. Banyumas Jawa

Tengah

Email: penerbit.penapersada@gmail.com Website:

penapersada.com Phone: (0281) 7771388

\section{Anggota IKAPI}

All right reserved Cetakan pertama: 2021

Hak Cipta dilindungi oleh undang-undang. Dilarang memperbanyak karya tulis ini dalam bentuk apapun tanpa izin penerbit 


\section{KATA PENGANTAR}

Segala puji senantiasa kita panjatkan kehadirat Allah Swt, atas segala rahmat dan karunianya, akhirnya penulis dapat menyelesaikan penyusunan buku yang berjudul "FAKTORFAKTOR YANG MEMPENGARUHI KUALITAS SISTEM INFORMASI AKUNTANSI ZAKAT", Bahwa tanpa bantuan dan bimbingan dari berbagai pihak sangatlah sulit bagi saya untuk menyelesaikan karya ini. Oleh karena itu, saya mengucapkan banyak terima kasih pada semua pihak yang telah membantu penyusunan buku ini. Sehingga buku ini bisa hadir di hadapan pembaca.

Kualitas Sistem Informasi Akuntansi merupakan hal yang sangat penting bagi suatu organisasi. Melalui Sistem Informasi Akuntansi yang berkualitas, user akan memperoleh informasi yang berkualitas pada saat yang tepat untuk pengambilan keputusan. Fenomena yang terjadi pada organisasi di Indonesia menunjukkan bahwa sistem informasi akuntansi belum berkualitas sehingga berdampak pada belum berkualitasnya informasi akuntansi.

Penulis menyadari bahwa buku ini masih jauh dari kesempurnaan. Oleh karena itu kritik dan saran yang membangun sangat dibutuhkan guna penyempurnaan buku ini. Akhir kata saya berharap Allah Swt berkenan membalas segala kebaikan semua pihak yang telah membantu

Penulis 


\section{DAFTAR ISI}

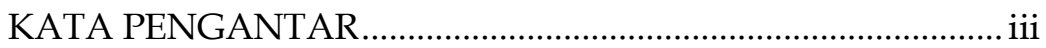

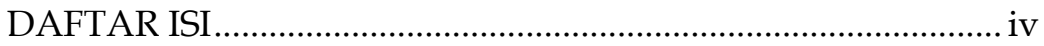

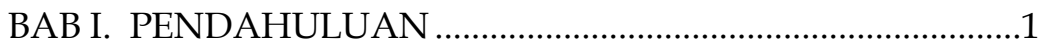

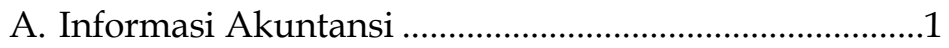

B. Problematika Sistem Informasi Akuntansi .....................4

BAB II. KEPEMIMPINAN TRANSFORMASIONAL ....................9

A. Definisi Kepemimpinan Transformasional.....................9

B. Dimensi dan Indikator Kepemimpinan

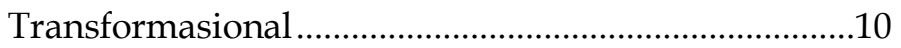

C. Pengaruh Kepemimpinan Transformasional terhadap Kualitas Sistem Informasi Akuntansi ...........14

BAB III STRUKTUR ORGANISASI........................................17

A. Definisi Struktur Organisasi ..........................................17

B. Elemen Struktur Organisasi ..........................................18

C. Pengaruh Struktur Organisasi Terhadap Kualitas Sistem Informasi Akuntansi..........................................21

BAB IV. KOMPETENSI PENGGUNA …....................................23

A. Konsep Kompetensi Pengguna.......................................23

B. Indikator dan karakteristik yang membentuk kompetensi 24

C. Pengaruh Kompetensi Pengguna terhadap Kualitas Sistem Informasi Akuntansi...........................................28

BAB V. KUALITAS SISTEM INFORMASI AKUNTANSI ..........31

A. Konsep Sistem Informasi ................................................

B. Sistem Informasi Akuntansi ............................................33

C. Kualitas Sistem Informasi Akuntansi .............................34

D. Pengaruh kualitas Sistem Informasi Akuntansi terhadap Kualitas Informasi Akuntansi .......................39

BAB VI. KEPEMIMPINAN TRANSFORMATIONAL DIBAZNAS

A. Gambaran Kepemimpinan Transformational dengan di Baznas.

1. Dimensi Idealized Influence /Charisma. 
2. Dimensi Intelectual Stimulation..................................46

3. Dimensi Individual Consideration .............................48

BAB VII. STRUKTUR ORGANISASI DI BAZNAS......................51

A. Gambaran Hubungan Struktur Organisasi di Baznas 51

1. Dimensi Formalisasi .................................................52

2. Dimensi Rentang Kendali/Span of Control .................54

3. Dimensi Departementalisasi .....................................55

BAB VIII. KOMPETENSI PENGGUNA SISTEM DI BAZNAS. 58

A. Gambaran Kompetensi Pengguna Sistem di Baznas 58

1. Dimensi Pengetahuan ...............................................59

2. Dimensi Keterampilan ................................................ 61

BAB IX. KUALITAS SISTEM INFORMASI AKUNTANSI

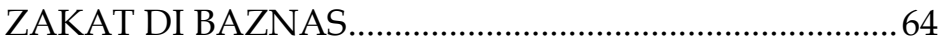

A. Gambaran Kualitas Sistem Informasi di Baznas..........64

1. Dimensi Integrasi/ Integration .....................................65

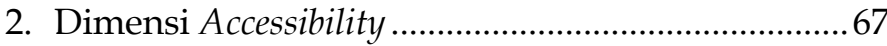

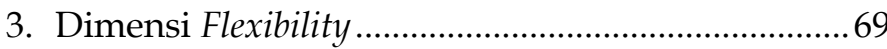

BAB X. MODEL KEBERHASILAN SISTEM INFORMASI

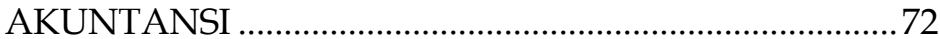

BAB XI. PENGARUH KEPEMIMPINAN

TRANSFORMASIONAL TERHADAP KUALITAS

SISTEM INFORMASI AKUNTANSI ZAKAT

DIBAZNAS 90

BAB XII. PENGARUH STRUKTUR ORGANISASI

TERHADAP KUALITAS SISTEM INFORMASI

AKUNTANSI ZAKAT DIBAZNAS. 98

BAB XIII. PENGARUH KOMPETENSI PENGGUNA

SISTEM TERHADAP KUALITAS SISTEM

INFORMASI AKUNTANSI ZAKAT DIBAZNAS ..........104

BAB XIV. KESIMPULAN DAN SARAN ................................110

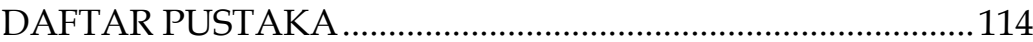




\section{FAKTOR-FAKTOR YANG MEMPENGARUHI KUALITAS SISTEM INFORMASI AKUNTANSI ZAKAT}




\section{BAB I. \\ PENDAHULUAN}

\section{A. Informasi Akuntansi}

Informasi merupakan data yang telah diolah menjadi bentuk yang bermanfaat dan berguna bagi para pengguna (Laudon \& Laudon, 2016:48). Hal yang sama diungkapkan oleh Azhar Susanto (2013:38) bahwa informasi adalah hasil dari pengolahan data yang memberikan arti dan manfaat. Lebih lanjut Azhar Susanto (2013:51) menjelaskan bahwa nilai suatu informasi tergantung kepada kualitas informasi yang disajikan. Informasi yang berkualitas merupakan salah satu keunggulan kompetitif bagi suatu organisasi ( $\mathrm{Xu}$, 2009:1). Semakin baik kualitas informasi yang dimiliki oleh suatu organisasi, maka akan semakin baik pula komunikasi yang terjadi didalamnya (Azhar Susanto, 2013:11).

McLeod \& Schell (2007:35), mengatakan bahwa informasi yang berkualitas apabila memenuhi kriteria akurat, tepat waktu, relevan dan lengkap. Sementara Romney \& Steinbart (2015:30) menyatakan bahwa informasi yang berkualitas dapat dilihat dari kriteria relevant, reliable, complete, timely, understandable, verifable dan accessible. Informasi dikatakan relevan apabila informasi yang diberikan kepada pengguna sesuai dengan yang dibutuhkan oleh individu di berbagai tingkatan dan bagian dalam organisasi (Azhar Susanto, 2013:38). Selanjutnya informasi dikatakan akurat apabila informasi terbebas dari pengertian yang menyesatkan dan kesalahan material, serta informasi tersebut menyajikan setiap fakta secara jujur dan dapat diverifikasi (McLeod \& Schell, 2007:35), berikutnya informasi dikatakan tepat waktu apabila informasi yang disajikan tersedia setiap saat ketika dibutuhkan bagi 
pengambilan keputusan (Romney \& Steinbart, 2015:30). Sedangkan informasi dikatakan lengkap jika informasi yang dihasilkan telah selengkap apa yang diinginkan dan dibutuhkan pengguna (Azhar Susanto, 2013:13).

Fenomena di lapangan menunjukkan bahwa kualitas informasi akuntansi yang digunakan dalam suatu lembaga/perusahaan masih rendah (Fuad Rahmany, 2014; Ali Maskur Musa, 2014; Agus Martowardojo, 2013; Fuad Nashar, 2013; Hadi Poernomo,2014; Reydonnyzar Moenek, 2015). Pada perusahaan sektor publik, sebagaimana yang diungkapkan oleh Ketua Komite Perpajakan, Fuad Rahmany (2014), bahwa tidak optimalnya penerimaan pajak karena belum akuratnya data NPWP. Hal serupa juga dikatakan oleh anggota IV Badan Pemeriksa Keuangan, Ali Masykur Musa (2014), bahwa data yang berkaitan dengan produksi mineral dan batubara sangat lemah atau tidak akurat. Informasi yang tidak akurat mengakibatkan manajemen salah dalam mengambil keputusan (Ali Masykur Musa, 2014).Demikian pula yang diungkapkan oleh Agus Martowardojo (2013) bahwa terdapat 10 Kementrian/ Lembaga yang memiliki laporan keuangan yang tidak berkualitas.

Permasalahan lain yang berhubungan dengan rendahnya kualitas informasi akuntansi dikemukakan oleh Hadi Poernomo (2011) yang menyatakan bahwa 326 Pemda atau $91 \%$ dari 358 Pemda yang laporan keuangannya diaudit oleh BPK dinyatakan tidak berkualitas, hanya 32 Pemda yang mendapatkan opini wajar tanpa pengecualian. Demikian juga yang diungkapkan oleh Dirjen Keuangan daerah Kemendagri, Reydonnyzar Moenek (2015) yang menyatakan anggaran yang diajukan KPUD kepada pemerintah Daerah (Pemda) dinilai tidak relevan dan tidak rasional sehingga Pemda melakukan rasionalisasi dan prinsip kehati-hatian. Sementara Fuad Nasar (2013) Wakil Sekretaris Badan Amil Zakat Nasional (BAZNAS) Pusat 
menyatakan bahwa laporan keuangan/informasi akuntansi yang disampaikan oleh Baznas Kabupaten/Kota yang ada di seluruh Indonesia, masih banyak yang belum tepat waktu, yang berdampak penerimaan dana zakat masih rendah.

Melihat peran informasi yang begitu tinggi bagi organisasi maka organisasi menjadi tergantung pada sistem informasi akuntansi (Azhar Susanto, 2013:11). Hal yang sama diungkapkan oleh Wongsim \& Jing Gao (2011:1) bahwa informasi yang berkualitas dihasilkan oleh sistem informasi yang berkualitas. Hal ini senada dengan pernyataan O'Brien \& Marakas (2010:353) bahwa user membutuhkan informasi yang berkualitas karena informasi yang berkualitas akan meningkatkan nilai keputusan yang akan diambil oleh perusahaan.

Kualitas Sistem informasi dapat dinyatakan dengan karakteristik diantaranya (1) integrasi yaitu perpaduan/ penggabungan bagian-bagian atau komponen-komponen dari sistem dalam mencapai fungsi yang lebih baik sesuai dengan harapan (Norman, 2014:15; Heidmann, 2008:87) dan harmonis (Azhar Susanto, 2013: 73-83), (2) accessibility yaitu sistem mudah diakses (Stair \& Reynold, 2016:8; Laudon \&Laudon, 2016:505; Wixon \& Tod, 2005; Heidmann, 2008:89), (3) flexibility yaitu kemampuan sistem untuk melakukan penyesuaian atau beradaptasi terhadap perubahan kebutuhan sistem (Heidmann, 2008:88; Peter, 2008; Weygandt et.al, 2012:316; DeLone \& McLean, 2003:13) dan (4) .ease of use yaitu sistem mudah digunakan (Romney \& Steinbart, 2012:615; Wixom \& Tod, 2005:88; DeLone \& McLean, 2003:13),

Integrasi merupakan penggabungan bagian-bagian dasar dari sistem secara bersama sama bersinergi untuk mencapai fungsi atau kegunaan yang lebih tinggi atau sesuai harapan (Norman, 2014:15). Lebih lanjut dikatakan bahwa integrasi sistem mencakup integrasi komponen dan integrasi fungsi (Norman, 2014:15). 


\section{B. Problematika Sistem Informasi Akuntansi}

Kenyataan dilapangan khususnya di Badan Amil Zakat Nasional (BAZNAS), sebagaimana yang diungkapkan oleh Fuad Nashar (2013) sekretaris BAZNAS Pusat bahwa belum tertatanya sistem pelaporan zakat yang terintegrasi secara nasional mengakibatkan laporan keuangan BAZNAS kabupaten dan kota seluruh Indonesia tidak tepat waktu. Demikian pula yang dikemukakan Ketua BAZNAS Pusat (Didin Hafidhuddin, 2014), bahwa belum terintegrasinya database pemberi zakat (muzaki) dan penerima zakat (mustahik) mengakibatkan belum optimalnya penghimpunan dan penyaluran dana zakat di Indonesia. Senada dengan pendapat tersebut, Bambang Sudibyo (2014), menyatakan bahwa lemahnya sistem informasi akuntansi keuangan di BAZNAS salah satunya disebabkan tidak terintegrasinya data akuntansi, yang menyebabkan penerimaan dana zakat masih jauh dari potensi yang ada (Didin Hafidhuddin, 2013).

Belum efektifnya organisasi pengelola dana zakat dalam menghimpun dana zakat dan menyalurkan dana zakat disebabkan informasi yang belum berkualitas, dan sistem pelaporan keuangan dana zakat belum terintegrasi secara nasional (Fuad Nasar, 2013).Hal ini dipertegas kembali oleh Nana Minarti (2011) Direktur Indonesia Magnifence of Zakat (IMZ), masalah besar yang dihadapi oleh organisasi pengelola zakat, salah satunya masalah sistem informasi, dimana kebanyakan organisasi pengelola zakat tidak memahami pentingnya sistem informasi untuk meningkatkan kualitas informasi dan kinerja organisasinya. Untuk itu organisasi pengelola zakat dituntut mempunyai sistem informasi yang baik agar menghasilkan informasi yang berkualitas sehingga potensi zakat yang begitu besar dapat dihimpun dan diberdayakan secara maksimal (Ahmad Juwaini, 2011) Presiden Direktur Dompet Dhuafa. 
Permasalahan lain yang berhubungan dengan rendahnya kualitas sistem informasi akuntansi adalah sistem tidak mudah diakses, sebagaimana yang dikemukakan oleh Direktur LSM, Suroto (2016) bahwa Sistem Informasi Desa (SID) yang berkaitan dengan APBDes, RKPDes sulit diakses oleh masyarakat, sehingga masyarakat kesulitan memantau kebijakan Pemdes. Hal yang sama dikemukakan Wakil Sekretaris Badan Amil Zakat Nasional Pusat, Fuad Nasar (2014) menyatakan bahwa belum efektifnya BAZNAS dalam menghimpun dana masyarakat karena sistem tidak mudah diakses oleh masyarakat, yang berdampak pada tingkat penerimaan dana zakat yang rendah, dimana tahun 2014 baru mencapai 3,2 triliun padahal potensi zakat di Indonesia bisa mencapai 217 triliun yang terdiri dari sumber zakat rumah tangga muslim sebesar 82 triliun dan perusahaan swasta sebesar 114,89 triliun (Bambang Sudibyo, 2015), hanya 1,4\% dari potensi yang diterima (Teten Kustiawan, 2015) Direktur pelaksanaan Baznas.

Rendahnya kualitas sistem informasi dapat disebabkan beberapa faktor, diantaranya struktur organisasi, sebagaimana yang dinyatakan oleh Stair \& Reynolds, 2010:48; Laudon \& Laudon, 2016:598; Scott, 2001:6; Wongsim \& Gao, 2011:2, bahwa kualitas sistem informasi akuntansi dipengaruhi oleh struktur organisasi. Struktur organisasi adalah susunan yang menunjukkan hirarki organisasi untuk menjalankan wewenang dan tanggung jawab serta koordinasi di antara mereka agar tujuan organisasi tercapai (Mc Shane \& Glinow, 2010:386; Colquitt, et al.,2015:504; Robbins \& Judge, 2014:231). Menurut Scott (2001:6), bahwa struktur organisasi mempengaruhi sistem informasi, sehingga ketika terjadi perubahan organisasi yang melibatkan sistem baru maka struktur organisasi menjadi penting untuk diperhatikan. Hal senada diungkapkan oleh Batool (2011) bahwa struktur organisasi merupakan salah 
satu faktor yang berpengaruh terhadap sistem informasi akuntansi yang berkualitas. Demikian pula menurut Salehi \& Abdipour (2013:304) bahwa struktur organisasi merupakan salah satu yang mempengaruhi hambatan dalam kegagalan pelaksanaan sistem informasi akuntansi, dimana struktur organisasi yang tidak baik akan mengakibatkan tidak terkoordinasinya aktivitas organisasi, tumpang tindih dan berjalan sendiri-sendiri (Soetipto, 2004).

Menteri Pendayagunaan Aparatur Negara dan Reformasi Birokrasi (PAN \& RB), Azwar Abu Bakar (2012) menyatakan bahwa struktur organisasi yang terlalu besar mengakibatkan tugas dan fungsi menjadi tumpang tindih, tidak professional, dan bahkan menghabiskan anggaran besar. Demikian pula diungkapkan oleh Wakil Ketua Fraksi PKS Bidang Ekonomi dan Keuangan Shohibul Iman (2012), bahwa struktur organisasi yang terlalu gemuk, menyebabkan eksekusi kebijakan menjadi lambat dan banyak tumpang tindih. Lebih lanjut dikatakan bahwa perampingan struktur organisasi akan sangat bagus untuk meningkatkan kecepatan eksekusi kebijakan dan meningkatkan kualitas sistem (Sohibul Iman,2012).

Selain struktur organisasi, sistem informasi akuntansi juga dipengaruhi oleh kepemimpinan transformasional (Cho et al ,2011). Kepemimpinan transformasional adalah pemimpin yang mampu mempengaruhi orang lain untuk mencapai kinerja yang lebih baik (Schemerhorn, 2010:324). Tujuan kepemimpinan transformasional adalah menerapkan sistem informasi yang efesien dan efektif (Koehler et.al.,1997:17). Hal ini senada seperti yang dikemukakan (Cho et.al., 2011), bahwa kepemimpinan transformasional berpengaruh positif terhadap keberhasilan sistem informasi akuntansi. Lebih lanjut Cho, et.al., (2011) menyatakan bahwa kepemimpinan transformasional dapat meningkatkan sistem informasi akuntansi melalui (1) idealized influence, (2) inspirational motivation, (3) individualized consideration, (4) 
intellectual stimulation. Robbin \& Judge (2014:197) menyatakan bahwa kepemimpinan transformasional lebih unggul dibandingkan dengan kepemimpinan transaksional, karena kepemimpinan transformasional menghasilkan tingkat upaya dan kinerja para pengikut yang melampaui apa yang bisa dicapai, jika pemimpin hanya menerapkan pendekatan transaksional.

Kenyataan dilapangan, tidak sedikit perusahaan besar yang jatuh dan tutup karena tidak dikelola dengan baik oleh seorang pemimpin (Andreas Budiharjo, 2013), Lebih lanjut Andreas Budiharjo (2013) menyatakan bahwa kepemimpinan yang tepat membuat perusahaan mampu mencapai sasarannya, menganalisis dan memprediksi situasi masa depan serta menentukan misi, visi, dan sasaran yang akan dicapai, oleh karena itu seorang pemimpin harus menjadi panutan dan senantiasa tak henti menginspirasi dan mentransformasi nilai- nilai positif dalam menghadapi perubahan organisasi, inovatif, profesional, dan integritas (Andreas Budiharjo, 2013). Hal ini senada yang dikemukakan Ghandour et .al., (2007) bahwa keberhasilan dan kesuksesan usaha kecil dan menengah (UKM) dalam implementasi sistem informasi tergantung pada peran penting seorang pemimpin.

Faktor lain yang dapat mempengaruhi kualitas sistem informasi akuntansi adalah kompetensi pengguna (Laudon \& Laudon, 2012:84; O’Brien \& Marakas,2010:68). Kompetensi merupakan karakteristik yang mendasari individu sehingga mampu bekerja secara efektif dan mempunyai kinerja unggul dalam pekerjaannya (Spencer \& Spencer, 1993:9).

Kompetensi pengguna dalam hal ini knowledge/ pengetahuan merupakan bagian terpenting dalam keberhasilan sistem informasi akuntansi (O'Brien \& Marakas, 2010:32). Hal ini diperkuat hasil penelitian sebelumnya yang membuktikan bahwa kompetensi pengguna merupakan faktor penting dalam kesuksesan 
sistem informasi akuntansi (Daoud \& Triki, 2013:1-35).

Fenomena/permasalahan yang berhubungan dengan kompetensi masih banyak terjadi di Indonesia, antara lain dikemukakan oleh Nusron Wahid (2013) anggota Komisi XI DPR RI menyatakan bahwa lemahnya kemampuan sumber daya manusia (SDM) yang bergelut dalam pengembangan produk syariah, berdampak pada nilai kapitalisasi pasar perbankan syariah di Indonesia sebesar 2,763 Triliun masih belum mencapai titik yang ideal. Dengan kata lain jumlah kapitalisasi pasar perbankan baru mencapai $5 \%$, sedangkan negara - negara tetangga lainnya misalnya Malaysia sudah mencapai 28 persen dari kapitalisasi perbankan Nasional (Nusron Wahid,2013). Selanjutnya Moch Yasin (2014) mantan Wakil Ketua KPK, menyoroti kinerja organisasi pengelola zakat belum optimal yang disebabkan lemahnya kualitas sumber daya manusia (SDM). Demikian juga yang terjadi di Badan Amil Zakat Nasional (BAZNAS), sebagaimana yang dikemukakan oleh direktur Indonesia Magnifence of Zakat (IMZ) Nana Mintarti (2011), menyatakan bahwa SDM memang menjadi kendala dalam pengembangan BAZNAS daerah. Ia menuturkan tak semua BAZNAS daerah digerakkan oleh tenaga full time, sehingga menjadi penghambat dalam pengembangan BAZNAS. Sebagai bukti keseriusan, Agus Martowardojo (2015) Gubernur Bank Indonesia mengatakan harus ada bentuk kerjasama yang tertuang dalam kesepahaman salah satunya adalah meningkatkan kualitas sumber daya manusia (SDM) sehingga Badan Amil Zakat Nasional (BAZNAS) menargetkan penghimpunan dana zakat tahun 2015 sebesar 5 Triliun dapat tercapai (Didin Hafidhudin, 2015). 


\section{BAB II. \\ KEPEMIMPINAN TRANSFORMASIONAL}

\section{A. Definisi Kepemimpinan Transformasional}

Kepemimpinan transformasional menurut Gibson \& Ivancevich et al., (2012:356), adalah pemimpin yang memotivasi para pengikutnya agar bekerja bukan untuk tujuan jangka pendek, bukan untuk kepentingan pribadi dan keamanan tetapi untuk prestasi dan aktualisasi diri. Hal senada diungkapkan oleh Yukl (2010:277) bahwa kepemimpinan transformasional membuat pengikut lebih peka terhadap nilai dan pentingnya pekerjaan, mengaktifkan kebutuhan-kebutuhan pada tingkat yang lebih tinggi dan mendahulukan kepentingan organisasi dan berdampak pada kepercayaan, rasa hormat, serta termotivasi untuk melakukan sesuatu lebih dari yang diharapkan..

Kepemimpinan transformasional memberi inspirasi tentang nilai-nilai, keyakinan dan cita-cita dan pada akhirnya memotivasi para pengikutnya untuk melaksanakannya melebihi dari apa yang diharapkan (Avolio, et al, 2004). Melalui pendekatan kepemimpinan transformasional ini, akan membuat para pengikut menjadi percaya, loyal, dan hormat kepada pemimpin serta seringkali mengabaikan kepentingan pribadi mereka untuk mencapai kepentingan kelompok (Avolio, et al,2004) Mereka juga berpikiran positif, optimis dan seimbang secara emosional serta mampu mengatasi stress dan lingkungan yang kompleks (Bass \& Ringgio, 2006:168).

Schermerhon (2010: 324) menyatakan bahwa kepemimpinan transformasional adalah pemimpin inspirasional yang mampu membuat orang-orang untuk berbuat lebih banyak dalam mencapai target yang 
diharapkan (transformational leadership occurs when leaders broaden and elevate followers interest and stir followers to look beyond their own interests to the good of others). Sementara Robbin \& Judge (2014:189) mengatakan bahwa pimpinan transformasional adalah pemimpin yang menginspirasi para pengikutnya untuk mengesampingkan kepentingan pribadi mereka demi kebaikan organisasi dan mereka mampu memiliki pengaruh yang luar biasa pada diri para pengikutnya. Mereka menaruh perhatian terhadap kebutuhan pengembangan diri para pengikutnya, merubah kesadaran para pengikutnya atas isu-isu yang ada dengan cara membantu orang lain memandang masalah lama dengan cara yang baru, serta mampu menyenangkan hati dan menginspirasi para pengikutnya untuk bekerja keras guna mencapai tujuan bersama (Robbin \& Judge, 2014:185188).

Berdasarkan pendapat para ahli yang telah dikemukakan diatas, maka dapat disintesakan bahwa kepemimpinan transformasional adalah pemimpin yang mampu untuk menginspirasi, memotivasi, mengarahkan, dan merubah sikap dan perilaku bawahannya agar memiliki kesadaran moral dan etika untuk bekerja secara maksimal dalam pencapaian tujuan organisasi.

\section{B. Dimensi dan Indikator Kepemimpinan Transformasional}

Adapun dimensi dan indikator dari kepemimpinan transformasional sebagaimana yang dikatakan oleh beberapa ahli, diantaranya menurut Avolio, et al. (2002), menyatakan bahwa karakteristik kepemimpinan transformasional terdiri dari 4 komponen I's antara lain : "idealized influence, inspirational motivation, intellectual stimulation, and individualized consideration". Hal ini senada dengan yang diungkapkan oleh Cho, et al., (2011) bahwa kepemimpinan transformasional dapat meningkatkan keberhasilan organisasi (sistem informasi) melalui 4 
komponen yaitu: (1) Idealized influence; (2) Inspirational motivation; (3) Individualized consideration; (4) Intelectual stimulation.

Selanjutnya Robbin \& Judge (2014:188); Yulk, (2010) ; Lussier \& Achua, 2010:350) menyatakan bahwa karakteristik pemimpin transformasional meliputi:

1. Idealized influence/Charisma: menyediakan visi dan misi, mampu menanamkan kebanggaan, mampu mendapatkan rasa hormat dan kepercayaan (Idealized influence: provides vision and sense of mission, instills pride, gains respect and trust)

2. Inspirational motivation: mengkomunikasikan harapan, menggunakan simbol/lambang untuk memfokuskan pekerjaan, menyampaikan tujuan yang penting dengan cara sederhana (inspirational motivation: communicates high expectations, uses symbols to focus efforts, expresses important purposes in simple ways)

3. Intellectual Stimulation: meningkatkan kecerdasan, rasionalitas, dan pemecahan masalah secara hati-hati (Intelecctual stimulation: promotes intelligence, rationality, and careful problem solving)

4. Individualized Consideration: memberikan perhatian untuk setiap pribadi, memperlakukan setiap karyawan berdasarkan kemampuan individu, bersikap sebagai pelatih, penasehat (individualized consideration:gives personal attention, treats each employee individually, coaches, advises)

Hal yang sama dikemukakan oleh Mejia, et al., (2012:360) bahwa karakteristik kepemimpinan transformasional terdiri dari:

1. Inspire other people to follow a vision articulated by the leader

2. Make followers feel good and proud about identifying with leader 
3. Make followers trust the leader, sacrificing themselves if necessary to accomplish the leaders agenda

4. Make followers question status quo, buying into the leader's solutions to problems aassociated with current state of affairs

5. Make followers feel that their individual needs and abilities are understood by the leader and that the leader empowers them and energizes them to get better

Bertocci (2009:49), menyebutkan karakteristik kepemimpinan transformasional antara lain;

1. Charisma. Pemimpin transformasional mampu menanamkan rasa nilai, rasa hormat dan bangga, serta dapat mengartikulasikan visi (the leaders is able to insill a sense of value, respect and pride, and to articulate a vision

2. Individul attention: pemimpin memperhatikan kebutuhan bawahan dan memberikan kegiatan-kegiatan yang berarti sehingga bawahan tumbuh secara pribadi yang profesional (the leader pays attention to follower's needs and assigns meaningful projects so followers grow personally and professionally)

3. Intellectual stimulation: pemimpin membantu bawahan memikirkan kembali cara rasional untuk memeriksa situasi dan mendorong bawahannya untuk menjadi kreatif (the leaderhelps followers rethink rational ways to examine a situation and encourages followers to be creative).

Sementara Schermerhorn, et al., (2010:324) menyatakan transformational leadership: charisma, inspiration, intellectual stimulation, and individualized consideration:

1. Charisma : mampu mencapai visi dan misi dan menanamkan kebanggaan, rasa hormat dan kepercayaan (provides vision and a sense of mission and it instills pride along with follower respect and trust)

2. Inspiration: mampu berkomunikasi dan memfokuskan upaya dan mengungkapkan tujuan penting dalam cara 
sederhana (communicates high expectations uses sysbols to focus and expresses important purposes in simple ways)

3. Intelectual stimulation: meningkatkan kecerdasan, rasionalitas dan memecahkan masalah dengan mendorong pemecahan masalah yang sulit secara hati hati (promotes intellegence, rationality and careful problem solving by for example, encouraging looking at very difficult problem in a new way)

4. Individualized consideration: memberikan perhatian secara pribadi dengan memperlakukan karyawan sesuai dengan individunya sendiri. (provides personal attention, treats each employee individually and coaches and advises)

Berdasarkan pendapat para ahli yang telah dikemukakan di atas, maka dimensi dan indikator kepemimpinan transformasional yang digunakan adalah:

1. Karismatik (Charisma /Idealized Influence) yaitu seorang pemimpin yang dapat mengembangkan ikatan emosional yang kuat dari pengikutnya dan mampu menanamkan rasa hormat, kebanggaan dan dapat mengartikulasikan visi, sehingga bawahan dapat bekerja secara maksimal (Lussier \& Achua, 2010:350; Bertocci, 2009:49; Yukl, 2010:276-278;

Luthans, 2011:430), dengan indikator sebagai berikut:

a. Mencapai Visi dan Misi (Robbins \& Judge, 2014:185189; Yukl, 2010:278; Cho, et al.,2011; Bertocci, 2009:49;

Hitt, et al., 2011:306; Mejia \& Balkin, 2012:359-360)

b. Menanamkan kepercayaan (Robbins \& Judge,2014:185- 189; Yukl ,2010:278; Cho et al.,2011; Mejia \& Balkin. 2012:359-360)

2. Stimulasi Intelektual/Intellectual stimulation yaitu pemimpin transformasional menstimulasi pengikut dan rekan-rekan untuk berpikir kreatif dan inovasi dan dapat membingkai masalah dengan hati-hati. (Bertocci, 2009:49; Luthan, 2011:430; Robbin \& Judge, 2014:188; Schermerhorn, 